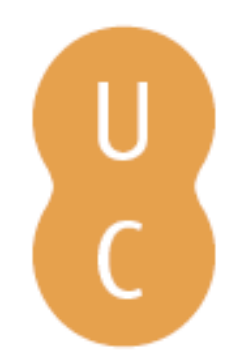

\title{
Rompalina
}

\section{Foraminíferos atuais do litoral de Benguela (Angola): diversidade e implicações ecológicas}
Autor(es):
Henriques, M. H.; Canales, M. L.; Mbadu, E.
Publicado por: Centro de Estudos Clássicos e Humanísticos da Universidade de Coimbra
URL persistente:
URI:http://hdl.handle.net/10316.2/31426
DOI:
DOI:http://dx.doi.org/10.14195/978-989-26-0534-0_20
Accessed : $\quad$ 26-Apr-2023 09:15:09

A navegação consulta e descarregamento dos títulos inseridos nas Bibliotecas Digitais UC Digitalis, UC Pombalina e UC Impactum, pressupõem a aceitação plena e sem reservas dos Termos e Condições de Uso destas Bibliotecas Digitais, disponíveis em https://digitalis.uc.pt/pt-pt/termos.

Conforme exposto nos referidos Termos e Condições de Uso, o descarregamento de títulos de acesso restrito requer uma licença válida de autorização devendo o utilizador aceder ao(s) documento(s) a partir de um endereço de IP da instituição detentora da supramencionada licença.

Ao utilizador é apenas permitido o descarregamento para uso pessoal, pelo que o emprego do(s) título(s) descarregado(s) para outro fim, designadamente comercial, carece de autorização do respetivo autor ou editor da obra.

Na medida em que todas as obras da UC Digitalis se encontram protegidas pelo Código do Direito de Autor e Direitos Conexos e demais legislação aplicável, toda a cópia, parcial ou total, deste documento, nos casos em que é legalmente admitida, deverá conter ou fazer-se acompanhar por este aviso.

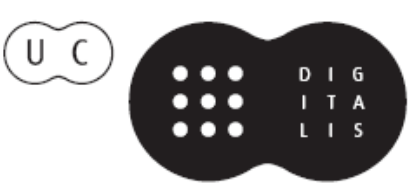





\title{
FORAMINÍFEROS ATUAIS DO LITORAL DE BENGUELA (ANGOLA): DIVERSIDADE E IMPLICAÇÓES ECOLÓGICAS
}

\author{
RECENT FORAMINIFERA FROM \\ THE BENGUELA COAST (ANGOLA): \\ DIVERSITY AND ECOLOGICAL IMPLICATIONS
}

M. H. Henriques ${ }^{1}$, M. L. Canales ${ }^{2} \&$ E. Mbadu ${ }^{3}$

Resumo - No presente trabalho descrevem-se as associações de foraminíferos bentónicos e planctónicos reconhecidas em sedimentos atuais do litoral de Benguela (Angola), a partir da amostragem realizada em cinco locais situados entre o Cuio (a sul) e o Lobito (a norte). A partir destes, foi possível conhecer a composição das associaçóes de foraminíferos e a sua diversidade, ao longo da costa, bem como inferir as condiçôes ambientais em que tais associaçóes se terão desenvolvido.

Do ponto de vista taxonómico, reconheceram-se 6 subordens, 22 famílias e 32 géneros, sendo muito abundantes nas associaçóes os representantes da Subordem Rotaliina, das Famílias Uvigerinidae, Rotaliidae e Elphidiidae e dos Géneros Uvigerina, Ammonia e Elphidium.

As associaçóes registadas nas amostras Benguela-1 e Benguela-2 são representativas de populaçôes desenvolvidas num ambiente marinho, pouco profundo, com salinidade abaixo do normal, eutrófico e aeróbico, e com temperatura correspondente à latitude. A primeira parece estar ligeiramente condicionada pela Corrente Fria de Benguela, enquanto a segunda não parece ter influência clara daquela corrente. A associação registada na amostra Benguela-3 é representativa de uma população desenvolvida em meio marinho, desde raso a plataforma, com salinidade normal, eutrófico, e com oxigénio variável (meio aeróbico nas zonas rasas e disaeróbico nas zonas mais profundas), com temperatura

1 Departamento de Ciências da Terra e Centro de Geociências; Faculdade de Ciências e Tecnologia da Universidade de Coimbra; 3000-272 Coimbra, Portugal; hhenriq@dct.uc.pt

${ }^{2}$ Departamento de Paleontología, Facultad de Ciencias Geológicas, Universidad Complutense de Madrid, Espańa; mcanales@geo.ucm.es

${ }^{3}$ Escola de Formação de Professores; Rua 10 de Fevereiro, Benguela, Angola; emilianambadu@yahoo.com 
correspondente à latitude, e com influência clara da Corrente Fria de Benguela. Nos pontos de amostragem correspondentes às amostras Benguela-4 e Benguela-5 nenhuma população de foraminíferos ficou registada, provavelmente devido a contaminação das águas derivada da atividade antrópica.

Palavras-chave - Foraminíferos atuais; Benguela; Angola; Ecologia

Abstract - The present work describes the benthic and planktonic foraminiferal assemblages recorded in Recent sediments along the Benguela coast (Angola), in five localities between Cuio (southern Benguela) and Lobito (northern Benguela). The obtained material has enabled the determination of the foraminiferal assemblages' composition and its diversity along the coast, as well as the environmental factors which have conditioned the assemblages' development.

From a taxonomic point of view 6 suborders, 22 families and 32 genera were recognized, the most abundant belonging to the suborder Rotaliina, the families Uvigerinidae, Rotaliidae and Elphidiidae, and the genera Uvigerina, Ammonia and Elphidium.

Benguela-1 and Benguela-2 assemblages represent populations which have been developed in shallow marine environments, displaying low salinity levels, eutrophic conditions and temperature levels corresponding to latitude. The first assemblage seems to be slightly conditioned by the Benguela Cold Current, unlike the second one. The Benguela-3 assemblage represents a population developed in shallow to platform marine environment, displaying normal salinity, eutrophic conditions and variable levels of oxygen supply (aerobic in shallow environments to disaerobic in deeper environments), temperature levels corresponding to latitude and the Benguela Cold Current seems to have clearly conditioned the assemblages' composition. From the samples Benguela-4 and Benguela-5, no record of foraminifera has been obtained, which can be probably related to water contamination resulting from anthropic activity.

Keywords - Recent Foraminifera; Benguela; Angola; Ecology

\section{1 - Introduçáo}

A análise da composição das associações de foraminíferos atuais tem grande aplicabilidade em investigações de carácter ecológico, uma vez que as variações naquelas refletem modificaçôes nas condiçóes ambientais, possibilitando, por exemplo, a monitorização de áreas sujeitas a poluição (VILELA, 2000).

O presente trabalho refere-se a uma investigação realizada no âmbito do Mestrado em Geociências da Universidade de Coimbra, centrada no estudo de associaçóes de foraminíferos atuais (bentónicos e planctónicos), que se obtiveram a partir de cinco amostras recolhidas no litoral da província angolana de Benguela (MBADU, 2011), entre as localidades de Cuio e Lobito (Fig. 1). Com ele, pretende-se contribuir para o conhecimento das associaçóes de foraminíferos atuais que se podem encontrar nesta parte do litoral de Angola, através da análise qualitativa e quantitativa daquelas associaçôes, bem como identificar os fatores que influenciam a sua distribuiçáo geográfica na referida área. 


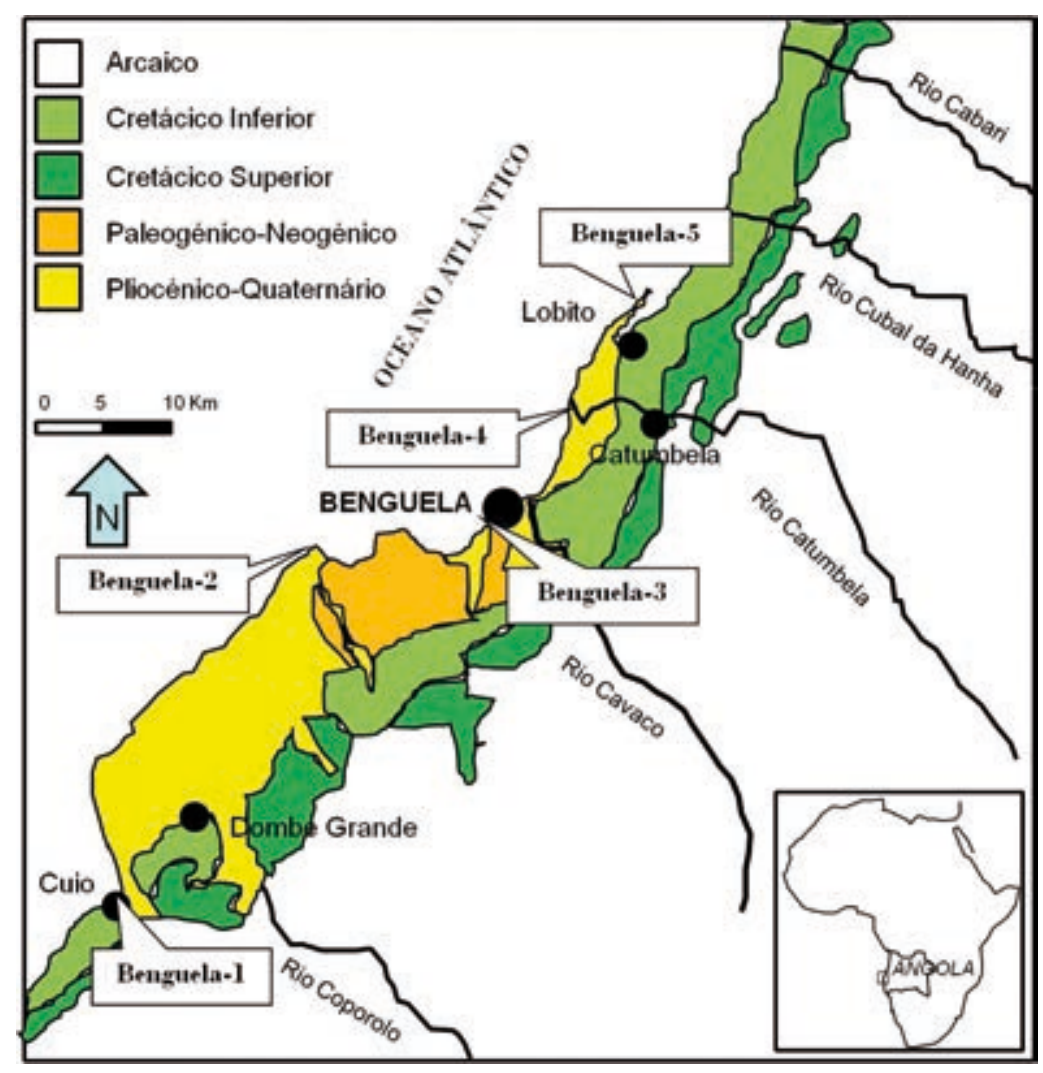

Fig. 1 - Localização da área de estudo e dos pontos de amostragem, utilizando a cartografia geológica de TAVARES et al. (2007).

Vários fatores condicionam a distribuição dos foraminíferos bentónicos atuais, tais como a temperatura, a profundidade, o tipo de substrato, a intensidade da luz que penetra nos oceanos, a energia da água, a topografia do fundo, a quantidade de terrígenos em suspensão e a salinidade, bem como a concentração de nutrientes e de oxigénio na água (AMSTRONG \& BRASIER, 2005; CALONGE \& CANALES, 2008). Quanto aos planctónicos, a sua distribuição geográfica é igualmente condicionada pela latitude, que se repercute na temperatura da água do mar.

Apesar do litoral de Angola se situar em posição latitudinal correspondente a temperaturas de massas de águas oceânicas superficiais relativamente quentes, a temperatura da água a 10 metros de profundidade é baixa, devido à ascensão de águas frias, transportadas pela Corrente Fria de Benguela. A Província de Benguela tem justamente o seu nome ligado a esta corrente de águas acompanhadas de ventos frios, que se movem no sentido sul-norte, e que banham a costa ocidental meridional de África, desde o Cabo da Boa Esperança (na África do Sul), passando pela Costa dos Esqueletos na Namíbia, e pela Costa de Angola, até alcançar o equador, onde vira rapidamente para oeste, para se transformar na Corrente Equatorial Sul (Fig. 2). 


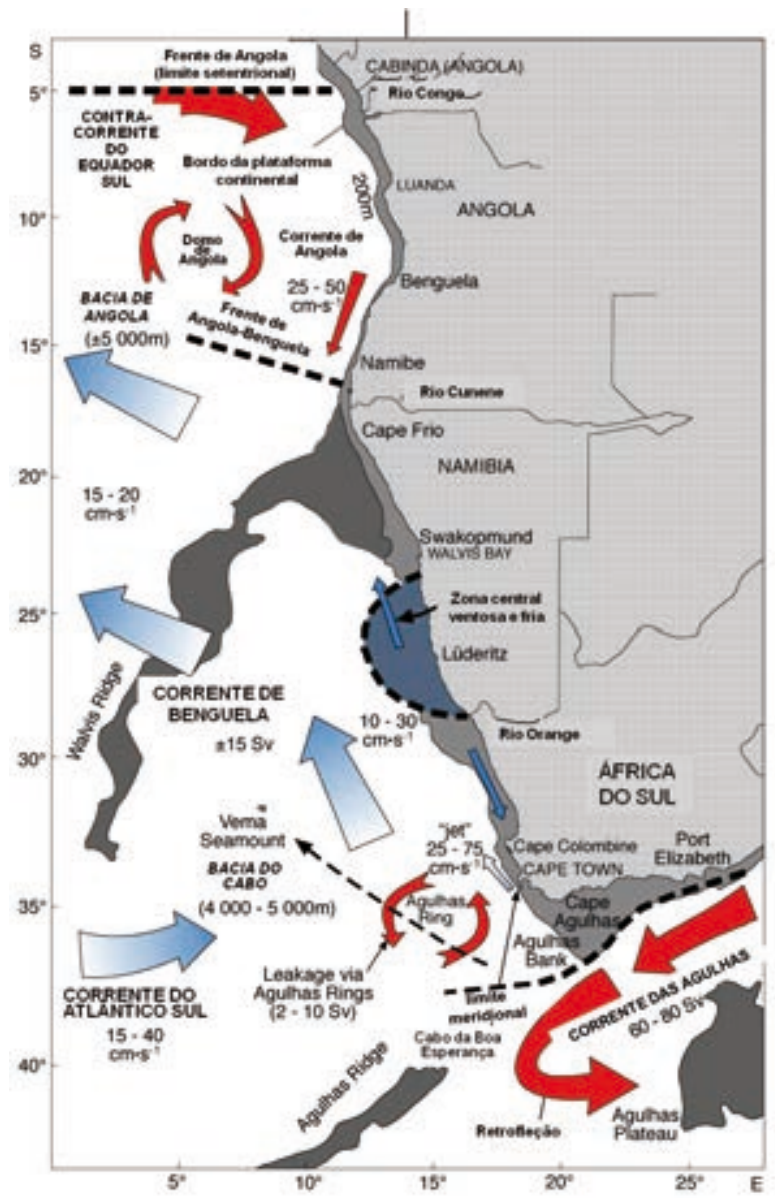

Fig. 2 - Limites internos e externos do Grande Ecossistema Marinho da Corrente Fria de Benguela, características batimétricas e correntes superficiais (modificado de SHANNON \& O’TOOLE, 2003).

Os ventos predominantes são de SE, e o Efeito de Coriolis leva a que as águas superficiais sejam defletidas offshore; estas são substituídas por águas profundas, mais frias e ricas em nutrientes, o que torna as águas do litoral de Benguela altamente produtivas, e das mais ricas do mundo em termos de recursos piscatórios (IOI-SA, 2011).

A Corrente Fria de Benguela representa um dos 64 grandes ecossistemas do mundo, cuja preservação constitui objeto de múltiplas iniciativas intergovernamentais (HOAGLAND \& JIN, 2006). De entre elas, destaca-se a Comissão da Corrente Fria de Benguela, uma organização constituída por Angola, Namíbia e África do Sul, e que visa promover a gestão integrada, desenvolvimento sustentável e proteção ambiental daquele Grande Ecossistema Marinho (BCC, 2011).

Com o presente trabalho pretende-se analisar a composição das associaçóes de foraminíferos bentónicos e planctónicos que atualmente habitam o litoral de Benguela, bem 
como inferir as condiçóes ambientais a que tais associaçóes estáo sujeitas, nomeadamente identificar locais que, devido a contaminação de origem antrópica, estão a pôr em risco o desenvolvimento daquelas populaçóes, contribuindo para a degradação dos habitats que integram o Grande Ecossistema Marinho da Corrente Fria de Benguela.

\section{1 - Enquadramento fisiográfico}

Do ponto de vista geomorfológico, a faixa costeira de Benguela é dominada pela presença de formas de relevo tabular, representando planaltos escalonados, constituídos por sedimentos carbonatados de idade cretácica, cortados por vales e rios (Cubal da Hanha, Catumbela, Cavaco e Coporolo), que definem uma topografia sensivelmente plana para sul, com camadas inclinadas em direção ao mar; os sedimentos terciários mergulham suavemente para noroeste, com pendores que raramente excedem $8^{\circ}$ a $10^{\circ}$ (TAVARES, 2000; TAVARES et al., 2007).

A regiáo litoral apresenta um relevo com depressóes aluviais e costeiras, separadas por arribas de erosão náo muito elevadas, onde se reconhecem dois terraços marinhos: o primeiro, elevado atualmente a cotas próximas dos $120 \mathrm{~m}$ a $150 \mathrm{~m}$ (plataformas a leste da cidade do Lobito), assenta sobre formaçóes cretácicas carbonatadas; o segundo, situado entre as cidades do Lobito e Benguela, desenvolve-se a cotas compreendidas até aos $40 \mathrm{~m}$, e corresponde a uma larga planície deltaica, com depósitos arenoargilosos, transportados e depositados pelo rio Catumbela (CARVALHO, 1960).

\section{2 - Materiais e métodos}

Foram recolhidas 5 amostras de sedimentos de praia, com aproximadamente 500 gramas de peso cada uma, cujas coordenadas estão representadas na Tabela 1.

Tabela 1 - Coordenadas geográficas dos locais amostrados para a realização do presente trabalho.

\begin{tabular}{cccc} 
Amostra & Localização & Latitude & Longitude \\
\hline Benguela 1 & Cuio - Dombe Grande & $12^{\circ} 58^{\prime} 29,45^{\prime \prime} \mathrm{S}$ & $13^{\circ} 59^{\prime} 06,11^{\prime \prime} \mathrm{E}$ \\
\hline Benguela 2 & Baia Farta - Dungo & $12^{\circ} 40^{\prime} 20,16^{\prime \prime} \mathrm{S}$ & $13^{\circ} 08^{\prime} 13,48^{\prime \prime} \mathrm{E}$ \\
\hline Benguela 3 & S. António - Benguela & $12^{\circ} 37^{\prime} 06,78^{\prime \prime} \mathrm{S}$ & $13^{\circ} 20^{\prime} 59,72^{\prime} \mathrm{E}$ \\
\hline Benguela 4 & Praia Bebé - Catumbela & $12^{\circ} 24^{\prime} 34,72^{\prime \prime} \mathrm{S}$ & $13^{\circ} 29^{\prime} 53,39^{\prime \prime} \mathrm{E}$ \\
\hline Benguela 5 & Restinga - Lobito & $12^{\circ} 18^{\prime} 55,86^{\prime} \mathrm{S}$ & $13^{\circ} 35^{\prime} 00,89^{\prime} \mathrm{E}$ \\
\hline
\end{tabular}

No laboratório, procedeu-se à descrição macroscópica das amostras recolhidas e, posteriormente, retiraram-se 150 gramas de cada uma, que foram separadas em quatro fraçôes $(>0,500 \mathrm{~mm},>0,250 \mathrm{~mm},>0,125 \mathrm{~mm},>0,063 \mathrm{~mm})$. Cada uma destas fraçôes foi pesada e arquivada, para posterior triagem. Esta foi realizada através da utilização de uma lupa binocular, modelo BMS-79457.

Os foraminíferos obtidos foram classificados, a nível de género, segundo a classificação de LOEBLICH \& TAPPAN (1988), e alguns dos exemplares dos táxones mais 
representativos foram fotografados ao microscópio eletrónico de varrimento, modelo JEOL 6400, no Centro Nacional de Microscopía Electrónica, situado na Universidade Complutense de Madrid (Espanha). O material estudado está arquivado no Laboratório de Paleontologia da Faculdade de Ciências e Tecnologia da Universidade de Coimbra (Portugal).

\section{2 - Resultados}

No conjunto das amostras estudadas, a subordem mais abundante é Rotaliina, com um total de 314 exemplares. A Subordem Lagenina atinge 59 exemplares e à Subordem Globigerinina são atribuíveis 27 carapaças. Da Subordem Miliiolina só foram obtidos 17 exemplares, e as subordens Robertinina e Textulariina podem ser consideradas minoritárias, com 4 e 3 exemplares respetivamente.

$\mathrm{Na}$ amostra Benguela-1 obtiveram-se 76 exemplares a partir de 58 gramas triadas, sendo a abundância de 1,3 foraminíferos por grama triada. Tendo em conta o número de exemplares obtidos (76) e de táxones identificados (4 subordens e 6 géneros) nesta associação, pode considerar-se que ela é representativa de uma biocenose pouco abundante, mas relativamente diversa (Fig. 3). Relativamente à sua composição, e segundo ARMSTRONG \& BRASIER (2005), a presença dos géneros Ammonia (dominante nesta associaçáo), Reophax, Elphidium (que tem endosimbiontes fotosintéticos) e Quinqueloculina, assim como a presença minoritária de formas planctónicas, indica que a associação se desenvolveu em águas pouco profundas. Os exemplares do género Ammonia podem viver em águas com salinidade mais baixa do que o normal. Este ponto de amostragem fica na zona de influência da desembocadura do Rio Coporolo, o que explicaria a dominância deste género na associação. Não se registaram exemplares pertencentes a géneros indicativos de condiçóes disaeróbicas, o que é concordante com um meio pouco profundo e, portanto, bem oxigenado. A pouca quantidade de exemplares com endosimbiontes (Elphidium) indica a presença de nutrientes suficientes no meio (eutrófico). A temperatura da água seria a correspondente à latitude, dada a escassez de formas planctónicas transportadas pela Corrente Fria de Benguela, que arrefeceria as águas se tivesse mais influência nesta área.
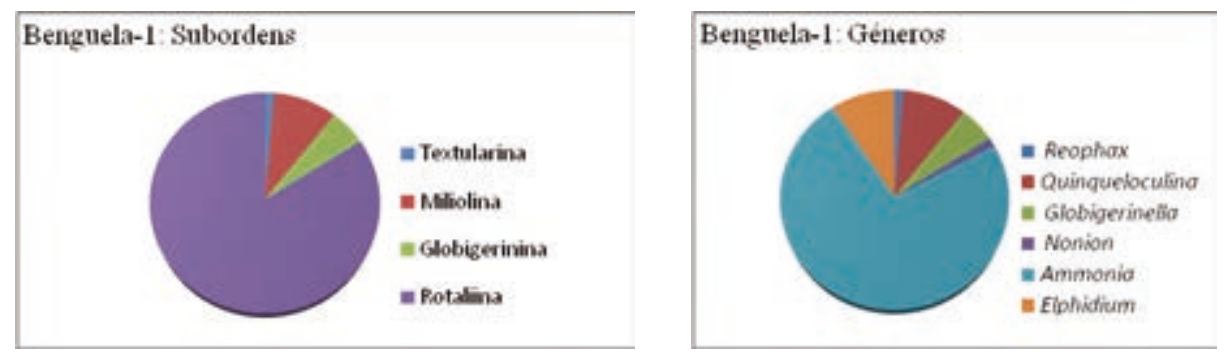

Fig. 3 - Percentagens das subordens e dos géneros de foraminíferos identificados na amostra Benguela-1.

$\mathrm{Na}$ amostra Benguela-2 obteve-se um total de 12 exemplares a partir de 58 gramas triadas, sendo a abundância de 0,2 foraminíferos por grama triada. A partir do número 
de exemplares obtidos (12) e de táxones identificados (3 subordens e 6 géneros) nesta associação, pode considerar-se que ela é representativa de uma biocenose muito pouco abundante, mas relativamente diversa (Fig. 4).

Nesta associação, a presença de um só exemplar planctónico e o predomínio de exemplares correspondentes aos géneros Ammonia, Elphidium e Cibicides são indicativos do desenvolvimento da mesma numa zona pouco profunda. A elevada abundância relativa dos géneros Ammonia e Elphidium parece indicar, da mesma maneira que na associação precedente, que a salinidade no meio é mais baixa do que o normal. É provável que a quantidade de nutrientes disponíveis seja menor nesta área do que na anterior, dado o maior número de exemplares pertencentes ao género Elphidium, que tem endosimbiontes fotossintéticos, o que reforça também os indícios de que a zona de desenvolvimento da associação corresponde a uma profundidade baixa. A ausência de táxones característicos de meios disaeróbicos (p.e., Bolivina, Bulimina ou Brizalina) indica que a quantidade de oxigénio dissolvido na água é normal. Não se registaram, nesta associação, exemplares de foraminíferos planctónicos transportados desde latitudes mais altas, pelo que a Corrente Fria de Benguela, nesta zona, não provoca arrefecimento das águas.
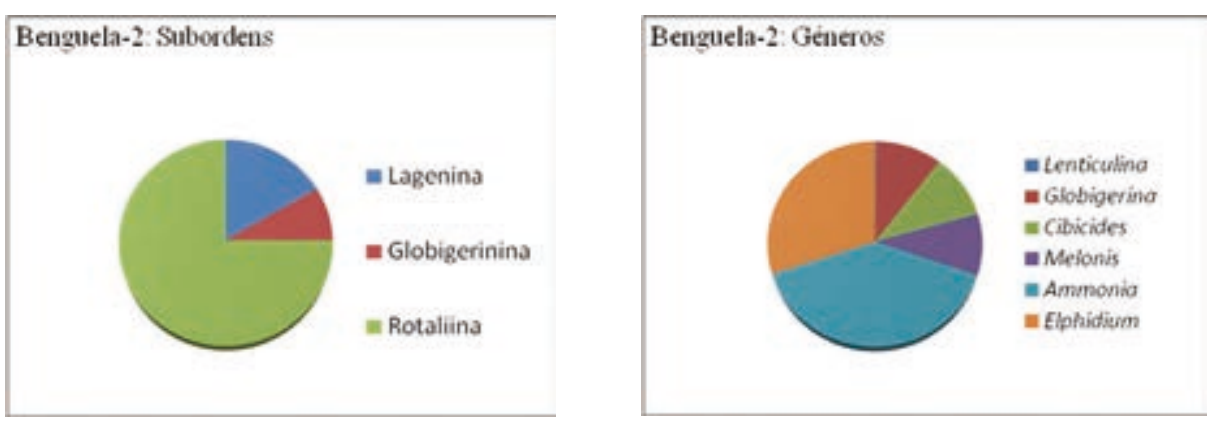

Fig. 4 - Percentagens das subordens e dos géneros de foraminíferos identificados na amostra Benguela-2.

$\mathrm{Na}$ amostra Benguela-3 obtiveram-se 336 exemplares, a partir de 59 gramas triadas, sendo a abundância de 5,7 foraminíferos por grama triada. Tendo em conta o número de exemplares obtidos (336) e de táxones identificados (6 subordens e 29 géneros), pode considerar-se que esta associação é representativa de uma biocenose abundante e muito diversa, incluindo táxones quer bentónicos, quer planctónicos (Fig. 5). Observa-se uma mistura de táxones que preferem condições pouco profundas (p.e., Quinqueloculina, Ammonia, Elphidium), com táxones calcários e aglutinados de zonas mais profundas (Bolivina, Bulimina, Uvigerina, Dorothia, Karreriella) e formas planctónicas de profundidades de até $100 \mathrm{~m}$ na coluna de água (Orbulina e Globigerina). Esta associação desenvolveu-se desde zonas pouco profundas até zonas relativamente profundas, em condições ambientais muito favoráveis para a sua proliferação, de plataforma marinha com salinidade normal, na qual os nutrientes são suficientes para permitir a existência de uma biocenose abundante e diversa, com táxones que têm endosimbiontes fotossintéticos e táxones calcários de carapaças pequenas e muito finas, que se desenvolvem em condiçôes eutróficas e disaeróbicas. As formas planctónicas obtidas nesta associação desenvolvem-se em latitudes subtropicais 
(Globigerina, Globigerinella, Globigerinoides e Orbulina), mas a presença de carapaças com enrolamento levógiro indica a influência da Corrente Fria de Benguela, pelo que as águas devem apresentar temperaturas mais baixas do que nas áreas correspondentes às das amostras Benguela-1 e Benguela-2.

Nas amostras Benguela- 4 e Benguela- 5 triaram-se 59 gramas de cada uma delas, mas ambas resultaram estéreis, não se tendo obtido qualquer carapaça de foraminífero. Tendo em conta os fatores ecológicos que podem condicionar as associaçóes de foraminíferos, ao longo do litoral de Benguela, náo parece que nenhum deles fosse suficientemente importante para impedir que houvesse registo destes micro-organismos nos locais correspondentes aos pontos de amostragem Benguela-4 e Benguela-5.
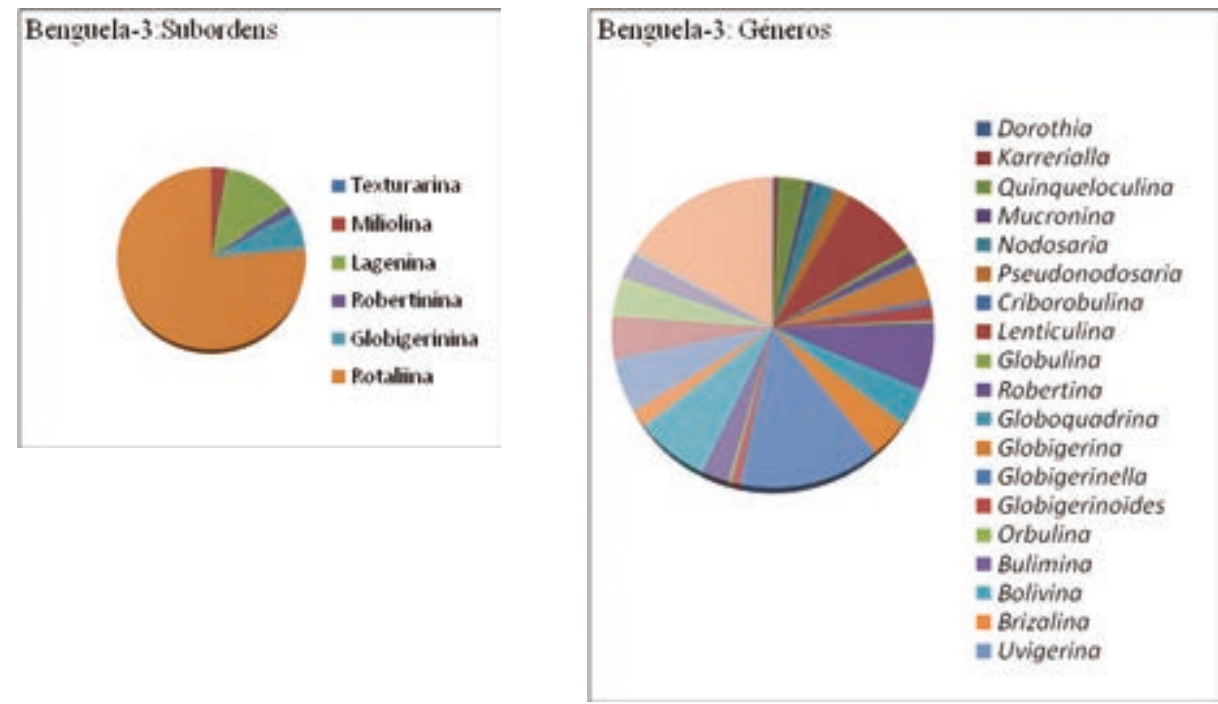

Fig. 5 - Percentagens das subordens e dos géneros de foraminíferos identificados na amostra Benguela-3.

A amostra Benguela- 4 foi recolhida na Praia Bebé, numa zona muito povoada, onde se desenvolvem atividades agrícolas e pesqueiras. É provável que a ausência de foraminíferos esteja relacionada com fatores antrópicos, nomeadamente com a contaminação das águas com resíduos urbanos ou com contaminantes provenientes dos adubos agrícolas. A demonstração desta hipótese fica sujeita a análises químicas das águas na região. Em relação à amostra Benguela-5, a situação poderia ser muito semelhante, dado que as correntes costeiras, do sul para o norte, poderiam deslocar os contaminantes, ou mesmo as areias que ali se depositam, e que não têm foraminíferos.

\section{3 - Conclusóes}

Os foraminíferos, e especialmente os microforaminíferos bentónicos, são considerados bons indicadores das condiçôes ambientais, pois colonizaram todos os ambientes 
marinhos, desde as lagunas salobras até aos fundos oceânicos (MURRAY, 1991). Dado que a sua mobilidade é reduzida, e que são organismos com preferências ambientais, as populaçóes refletem muito bem as mudanças que ocorrem no meio.

A partir da análise das composiçóes das associaçóes estudadas neste trabalho, é possível inferir as condiçóes ambientais nas quais puderam desenvolver-se as populaçóes de foraminíferos, cujas carapaças ficaram acumuladas, quer pelas marés, quer pela Corrente Fria de Benguela, nas areias do litoral de Benguela, analisando os diferentes fatores ambientais que as terão afetado.

A associação registada na amostra Benguela-1 é representativa de uma população desenvolvida num ambiente marinho, pouco profundo, com salinidade abaixo do normal, com suficientes nutrientes (condições eutróficas) e oxigénio (meio aeróbico), com a temperatura correspondente à latitude, e ligeiramente condicionada pela Corrente Fria de Benguela.

A associação registada na amostra Benguela-2 é representativa de uma população desenvolvida num ambiente marinho, pouco profundo, com salinidade abaixo do normal, com suficientes nutrientes (condições eutróficas) e oxigénio (meio aeróbico), com a temperatura correspondente à latitude, mas sem uma influência clara da Corrente Fria de Benguela.

A associação registada na amostra Benguela-3 é representativa de uma população desenvolvida num ambiente marinho, desde raso a plataforma, com salinidade normal, com suficientes nutrientes (condiçôes eutróficas) e oxigénio variável (meio aeróbico nas zonas rasas e disaeróbico nas zonas mais profundas), com a temperatura correspondente à latitude e com influência notável da Corrente Fria de Benguela.

Nos pontos de amostragem correspondentes às amostras Benguela- 4 e Benguela- 5 nenhuma população de foraminíferos ficou registada. A existência de populaçóes perto da praia em ambos os locais pode estar relacionada com a ausência de foraminíferos nestes pontos, consequência de contaminação das águas derivada de atividades de origem antrópica. Portanto, impóe-se a monitorização destas duas áreas, em termos da determinação de águas provavelmente contaminadas, com a consequente degradação duma parte do Grande Ecossitema Marinho da Corrente Fria de Benguela.

Agradecimentos - Este trabalho insere-no no âmbito das atividades dos projetos CGL2011-23947 - "Taxones Submediterráneos y Cambios Paleobiogeográficos en el Jurásico Medio de la Cordillera Ibérica” e CGL2008-03112 - “Crisis bióticas mesozoicas, entre el Triásico Superior y el Jurásico Medio, en el sistema de plataformas ibéricas. Eventos de extinción-renovación y cambios climáticos asociados”, do Ministerio de Educación y Ciencia (Espanha) e o trabalho de laboratório beneficiou do apoio do Consórcio Petrobras-Galp-Partex.

\section{Referências Bibliográficas}

AMSTRONG, H. \& BRASIER, M. D. (2005) - Microfossils. Blackwell Publ., 2nd ed., 296 p.

BCC (2011) - The Benguela Current Commission. United Nations Development Programme. http://www. bclme.org/ (consultado em 2011.11.24). 
CALONGE, A. \& CANALES, M. (2008) - El Mundo de los Microfósiles: Una propuesta de aula. In: Calonge, A., Rebollo, L., López-Carrillo, M. D. \& Rábano, I. (eds.). Actas del XV Simposio sobre Enseńanza de la Geología, Cuadernos del Museo Geominero, Inst. Geol. Min. Espańa, 11, p. 41-51.

CARVALHO, G. S. (1960) - Alguns problemas dos terraços quaternários do litoral de Angola. Bol. Serviços de Geologia e Minas de Angola, 2, p. 5-15.

HOAGLAND, P. \& JIN, D. (2006) - Accounting for Economic Activities in Large Marine Ecosystems and Regional Seas. UNEP Regional Seas Report and Studies No 181, 127 p. http://www.unep.org/regionalseas/ publications/reports/RSRS/pdfs/rsrs181.pdf (consultado em 2011.11.24).

IOI-SA (2011) - The Benguela Current. Train-Sea-Coast Course Development Unit Benguela Current. The International Ocean Institute. Southern Africa. http://www.ioisa.org.za/tsc/bcurrent.htm (consultado em 2011.11.24)

LOEBLICH, A. R. \& TAPPAN, H. (1988) - Foraminifera genera and their classification. Van Nostrand Reinhold Company, New York, 2, 970 p.

MBADU, E. (2011) - Foraminíferos actuais do litoral de Benguela (Angola). Tese de Mestrado, Departamento de Ciências da Terra, Faculdade de Ciências e Tecnologia da Universidade de Coimbra: 84p. (não publicado).

MURRAY, J. W. (1991) - Ecology and Palaeoecology of Benthic Foraminifera. Elsevier, Amsterdam, 397 p.

SHANNON, L. V. \& O'TOOLE, M. J. (2003) - Sustainability of the Benguela: ex Africa semper aliquid novi. In: Hempel, G. \& Sherman, K. (eds.). Large Marine Ecosystems of the World: Trends in Exploitation, Protection and Research, Elsevier, 10, p. 227-253.

VILELA, C. (2000) - Microfósseis - Parte I: Foraminíferos, Radiolários e Diatmáceas. In: Carvalho, I. S., (ed.). Paleontologia, Editora Interciência, Rio de Janeiro, 11, p. 157-183.

TAVARES, T. S. (2000) - Amonites de Angola. Sua ocorrência no Mesozóico das bacias sedimentares de Angola: Estratigrafia e Sistemática. Tese de Licenciatura, Universidade Agostinho Neto, Luanda: 137 p. (não publicado).

TAVARES, T. S., MEISTER, C., DUARTE-MORAIS, M. L. \& DAVID, B. (2007) - Albian ammonites of the Benguela Basin (Angola): a biostratigraphic Framework. South African Journal of Geology, 110, p. 137-156. 